Bulletin UASVM Food Science and Technology 70(2)/2013, 137-138

ISSN-L 2344-2344; Print ISSN 2344-2344; Electronic ISSN 2344-5300

\title{
The Physicochemical Quality of Traditional Burduf Cheese
}

\author{
Carmen POP*, Cristina Anamaria SEMENIUC, Sorin APOSTU, Ancuţa M. ROTAR \\ University of Agricultural Sciences and Veterinary Medicine Cluj-Napoca, Address - 400372 - Cluj- \\ Napoca, Mănăştur Street, number 3-5, România \\ *lazar_rody@yahoo.com
}

\begin{abstract}
The aim of this study is the assessment of the quality control of raw milk and traditional burduf cheese obtained from cow milk mixed with $10 \%$ sheep milk. Appreciation of the integrity and freshness assessment of milk (cow and sheep) was tested by physico-chemical analysis.

On the shelf-live were determined the physico-chemical parameters in cheese samples. The antibiotics residues were tested of the milk samples with portable analyser, model Rosa Charm Reader. The results of physico-chemical determinations for the milk and cheese samples were within the maximum permissible by data legislation. Regarding the content of antibiotics, the results were negative both for cow milk and for sheep milk. The sensory characteristics of burduf cheese are influenced by the different types of milk.
\end{abstract}

Keywords: burduf cheese, quality, cow milk, sheep milk.

Introduction. The quality of sheep's milk, which is used nearly exclusively for cheese production, is especially associated with its aptitude for clotting that is the ability to transform itself, with a high yield, into products with a high level of nutrition and good quality in terms of taste. Sheep's milk is particularly rich in useful constituents, and thus its cheese yield is nearly double (18-20\%) then the yield of goat's and cow's milk (Martini et al., 2008).

The remarkable quality of traditional cheeses is linked to milk fat content and fatty acid profile, as the number of volatile compounds that result from their degradation during maturation give specific aromas and savour (Mierlita et al., 2011).

Aim. The purpose of this study is the assessment of the quality control of raw milk and traditional burduf cheese obtained from cow milk mixed with $10 \%$ sheep milk.

Materials and methods. Appreciation of the integrity and freshness assessment of milk (cow and sheep) was tested by determining content of fat, nonfat dry matter, protein, density, freezing point, titratable acidity and $\mathrm{pH}$.

On the shelf-live were determined the content of fat, titratable acidity, total dry matter and $\mathrm{NaCl}$ in cheese samples.

The antibiotics residues were tested of the milk samples with portable analyser, model Rosa Charm Reader.

Results and discussions. The results of physicochemical determinations for the milk and cheese samples were within the maximum permissible by data legislation (as seen in Fig. 1 and Fig. 2). 


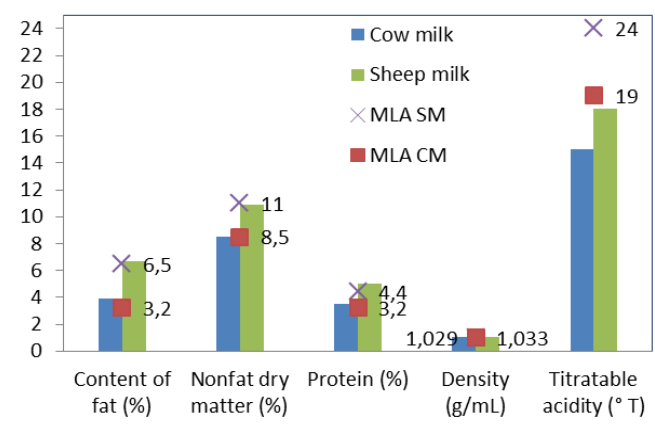

Fig. 1. Physico-chemical parameters of cow and sheep milk

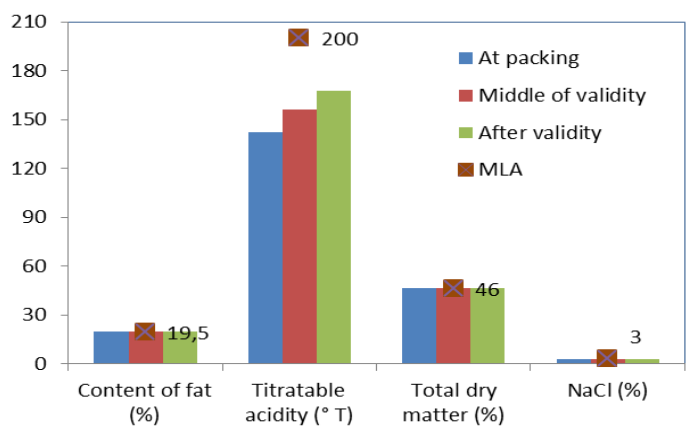

Fig. 2. Physico-chemical parameters of cheese from cow's milk mixed with $10 \%$ sheep's milk during and after the shelf-life

In raw milk was not identified any type of falsification.

Regarding the content of antibiotics, the results were negative both for cow and sheep milk.

Conclusion: The quality characteristics of burduf cheese are influenced by the different types of milk.

The quality of the milk used as raw material determines the quality of cheese, so as cow's milk and sheep's milk must be within the quality parameters stipulated by STAS in terms of both chemical composition and freshness.

\section{REFERENCES}

1. D. Mierlita, St. Daraban, F. Lup, 2011, Effects of breed on milk fatty acid profile in dairy ewes, with particular reference to cis-9, trans-11 conjugated linoleic acid, South African Journal of Animal Science, 41 (no. 3).

2. M. Martini, C. Scolozzi, F. Cecchi, M. Mele, F. Salari, 2008, Relationship between morphometric characteristics of milk fat globules and the cheese making aptitude of sheep's milk, Small Ruminant Research, Volume 74, Issues 1-3, Pages 194-201. 